\title{
Tidal Habitats Support Large Numbers of Invasive Blue Catfish in a Chesapeake Bay Subestuary
}

\author{
Mary C. Fabrizio ${ }^{1}$ (D) Troy D. Tuckey ${ }^{1} \cdot$ Robert J. Latour $^{1} \cdot$ Gary C. White $^{2}$. $^{-}$ \\ Alicia J. Norris ${ }^{1}$
}

Received: 3 March 2017 /Revised: 12 July 2017 / Accepted: 8 August 2017 /Published online: 22 August 2017

(C) The Author(s) 2017. This article is an open access publication

\begin{abstract}
The introduction of a non-native freshwater fish, blue catfish Ictalurus furcatus, in tributaries of Chesapeake Bay resulted in the establishment of fisheries and in the expansion of the population into brackish habitats. Blue catfish are an invasive species in the Chesapeake Bay region, and efforts are underway to limit their impacts on native communities. Key characteristics of the population (population size, survival rates) are unknown, but such knowledge is useful in understanding the impact of blue catfish in estuarine systems. We estimated population size and survival rates of blue catfish in tidal habitats of the James River subestuary. We tagged 34,252 blue catfish during July-August 2012 and 2013; information from live recaptures $(n=1177)$ and dead recoveries $(n=279)$ were used to estimate annual survival rates and population size using Barker's Model in a Robust Design and allowing for heterogeneity in detection probabilities. The blue catfish population in the 12-km study area was estimated to be 1.6 million fish in 2013 (95\% confidence interval [CI] adjusted for overdispersion: 926,307-2,914,208 fish). Annual apparent survival rate estimates were low: 0.16 (95\% CI 0.10-0.24) in 2012-2013 and 0.44 (95\% CI 0.310.58 ) in 2013-2014 and represent losses from the population through mortality, permanent emigration, or both. The tagged fish included individuals that were large enough to exhibit piscivory and represented size classes that are likely to
\end{abstract}

Communicated by Josianne G. Støttrup

Mary C. Fabrizio

mfabrizio@vims.edu

1 Virginia Institute of Marine Science, The College of William and Mary, Gloucester Point, VA 23062, USA

2 Department of Fish, Wildlife, and Conservation Biology, Colorado State University, Fort Collins, CO 80523, USA colonize estuarine habitats. The large population size that we estimated was unexpected for a freshwater fish in tidal habitats and highlights the need to effectively manage such species.

Keywords Mark recapture $\cdot$ Invasive species $\cdot$ Robust design $\cdot$ Coded wire tags $\cdot$ Individual heterogeneity

\section{Introduction}

In river-dominated estuaries, the continuum between freshwater and marine environments provides a potential conduit for the encroachment of freshwater species into brackish and saline habitats. Although higher salinities are believed to serve as a barrier to freshwater fishes (Scott et al. 2008), some species exhibit salinity tolerances that allow them to successfully colonize estuarine habitats. For example, blue catfish Ictalurus furcatus (Schloesser et al. 2011), Rio Grande cichlids Herichthys cyanoguttatus (Lorenz et al. 2016), African jewelfish Hemichromis letourneuxi (Rehage et al. 2015), largemouth bass Micropterus salmoides (Norris et al. 2010), and pikeperch Sander lucioperca (Scott et al. 2008) are freshwater species that are found in estuarine environments. Some of these freshwater fishes are non-native and considered invasive because they threaten the biodiversity of aquatic ecosystems (Arthington et al. 2016) through direct predation effects or indirectly by competition for limited resources with native fauna. Because estuaries are used as spawning and nursery areas by marine and estuarine fishes, invasive predatory fishes pose a particular concern (MacAvoy et al. 2009; Magoro et al. 2015). In Chesapeake Bay tributaries, diadromous fishes such as American shad Alosa sapidissima and alewife Alosa pseudoharengus, which have experienced significant coastwide declines in abundance, are vulnerable to predation by invasive blue catfish (MacAvoy et al. 2009; Schmitt et al. 
2017), a freshwater fish introduced into freshwater habitats of Chesapeake Bay tributaries in the 1970s and 1980s (Schloesser et al. 2011). Since the late 1990s, the abundance and spatial extent of blue catfish populations in the major subestuaries of Chesapeake Bay have increased (Schloesser et al. 2011), prompting management concerns and action.

Blue catfish are native to the Mississippi, Missouri, and Ohio river drainages but were introduced in the James, York, and Rappahannock rivers to establish recreational fisheries in Virginia. Within the Chesapeake Bay watershed, blue catfish have spread and are now found in the Piankatank, Potomac, Patuxent, Nanticoke, Sassafras, and Susquehanna rivers (Schloesser et al. 2011; M. Groves, MD Department of Natural Resources, pers. comm.); these occurrences may have been aided by natural events (e.g., flooding) or movement of fish by humans. In addition to freshwater habitats, blue catfish in the Chesapeake Bay region currently occupy estuarine habitats (Schloesser et al. 2011). Salinity tolerance and potential for adaptability of blue catfish is unknown, but we note that a single individual was recently collected from $21.8 \mathrm{psu}$ in the lower James River (Fabrizio and Tuckey, pers. obs.), suggesting that acute salinity tolerance may be quite high.

In Virginia subestuaries, where blue catfish have been established for $30-40$ years, eradication is not considered a feasible approach, and instead, management measures seek to control abundance and prevent further spread. One strategy commonly used for control of predatory fishes is to increase removals by commercial (e.g., Tsehaye et al. 2013) and recreational (e.g., Davis et al. 2012) fisheries. However, in some instances, fishing mortality rates on predators may be insufficient to realize a population-level effect on native forage species (Davis et al. 2012; Tsehaye et al. 2013). In other cases, selective removals of invasive fish may induce compensatory responses (e.g., earlier maturation) thereby reducing the efficacy of control measures (Evangelista et al. 2015). For invasive species that exhibit high site fidelity or habitat affinity (e.g., lionfish Pterois volitans), sufficiently high removal rates may be attained only locally, but not throughout the range (Barbour et al. 2011). In the Chesapeake Bay region, recreational fishery removals of blue catfish are not well estimated, and the commercial fishery is pursued by a few small-scale fishers; thus, exploitation rates are light, and possibly even negligible. Nevertheless, further development of these fisheries is desirable. Population models of blue catfish may be used to investigate the magnitude of fishery removals that are necessary to reduce the predatory impacts of blue catfish, but such models require an estimate of population size, which is currently unknown (Invasive Catfish Task Force 2015).

In this study, we sought to estimate the size of the invasive blue catfish population in the tidal freshwater region of the James River subestuary using mark-recapture methods. We also wished to estimate annual survival rates because such knowledge can provide insight on the dynamics of the population. We used a 3-year tagging study in 2012-2014 and analyzed the data using a modification of Pollock's robust design (Pollock 1982) developed by Barker (Barker 1997; Kendall et al. 2013). Barker's modification allows for dead recoveries (from the fishery) and live releases of recaptured fish. The robust design provides an estimate of the annual survival rate between two or more primary tagging periods, wherein the population is open, and an estimate of population size using observations from the secondary tagging sessions, wherein the population is considered closed (Fig. 1). Thus, the robust design combines attributes of open population models, which allow birth, death, immigration, and emigration rates to be nonzero, and closed models, wherein these rates are zero. In the robust design, estimates of survival rates are obtained using the Cormack-Jolly-Seber (CJS) model, whereas estimates of population size are obtained using closedpopulation models that do not require the assumption of equal catchability (Pollock et al. 1990; Kendall and Pollock 1992; White and Cooch 2017). However, the closure assumption is difficult to satisfy unless the period of study is short (e.g., on the order of days or a few weeks); thus, by sampling during brief weekly sessions in summer (during which closure applies), we attempted to meet the closure assumption.

\section{Methods}

\section{Fish Tagging}

Selection of the primary and secondary sampling periods for the robust design was guided by an understanding of movement patterns of blue catfish in their native range and the need to ensure secondary periods during which the population was closed. The primary samples of the robust design corresponded with sampling events in July-August 2012, 2013, and 2014 (Fig. 1); these time periods occurred at the putative conclusion of spawning and when migratory movements are expected to be minimal (Graham 1999). The long interval between successive primary periods ( 1 year) allowed additions and deletions to the population. In 2012, we tagged fish and monitored recaptures during a single secondary period. Within the 2013 primary period, we tagged and monitored (live) recaptures and (dead) recoveries during four closed sampling sessions (each of these secondary sessions corresponded to a 1-week period; Fig. 1). Fish from each of the four secondary samples were batch marked (the same tag placement was used for all fish in a given week), and intervals between and among the four successive secondary samples were sufficiently short to satisfy the closure assumption. After the completion of tagging in 2013, we monitored the commercial harvest for recoveries during an additional secondary sampling event ( $T_{5}$ in Fig. 1). In 2014, we did not tag fish, but we monitored the commercial harvest for recoveries during the single secondary period in that year. Thus, 


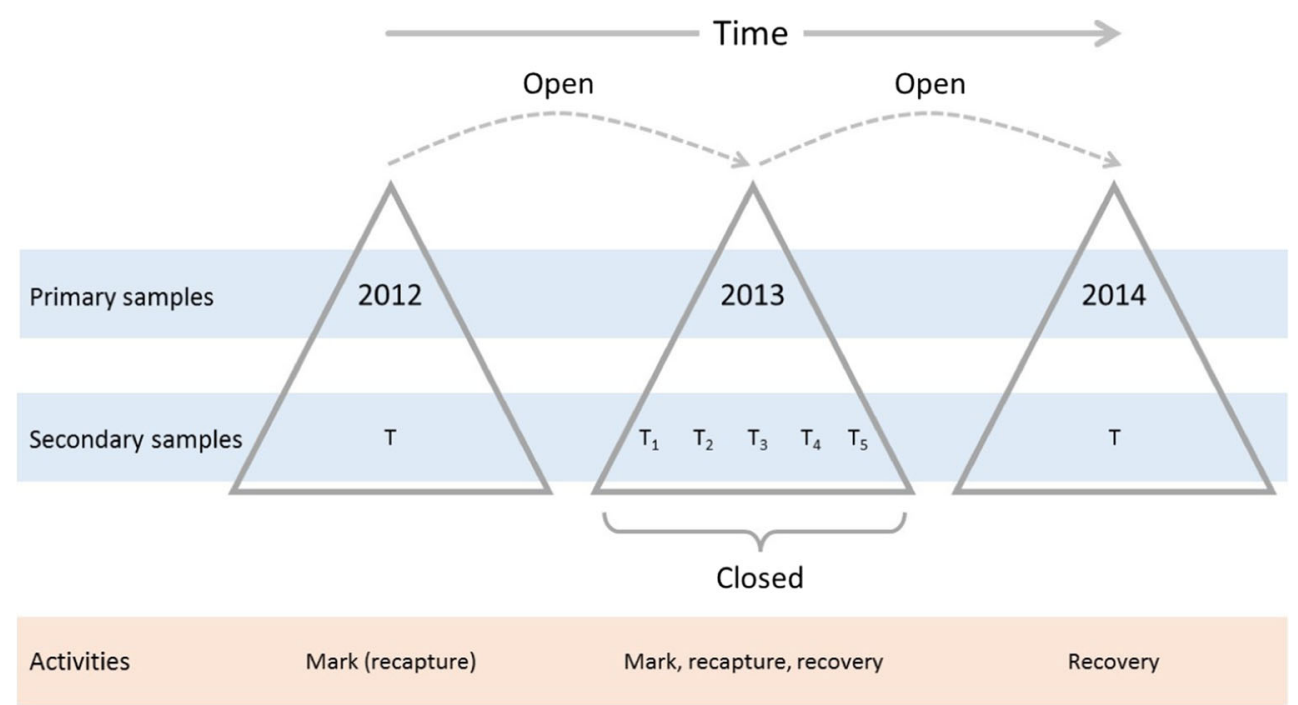

Fig. 1 Relationship between the primary (open) and secondary (closed) sampling periods in the robust design used to estimate survival rates and population size of invasive blue catfish in the James River subestuary, VA. We marked and released fish during a single secondary period, $\mathrm{T}$, in 2012 (8 Jul-4 Aug), and during four secondary occasions in 2013 ( $\mathrm{T}_{1}$ to
$\mathrm{T}_{4}$ corresponding with 20-26 Jul, 27 Jul-2 Aug, 3-9 Aug, and 10-16 Aug); we also monitored for recoveries during these occasions and during an additional secondary occasion in 2013 ( $T_{5}$ corresponding to 17-25 Aug). A single secondary period, $\mathrm{T}$, was used to monitor for recoveries in 2014 (7 Jul-22 Aug). Figure adapted from Kendall (2010) tagging and observation events in 2012 and 2014 occurred during a single secondary period, whereas in 2013, tagging and observation events occurred during multiple secondary periods.

We used coded-wire tags (CWTs; Northwest Marine Technology, Inc.) to mark blue catfish because CWTs generally have high retention rates, and automated tag applicators allowed efficient marking of large numbers of fish (Brennan et al. 2007; Hand et al. 2010; Simon and Doerner 2011; Lin et al. 2012; Ashton et al. 2014). To our knowledge, our use of CWTs in blue catfish represents the first application of these tags in this species and with relatively large (post-juvenile stage) fish. Taggers were either trained or experienced with operation of the automated tag applicator and achieved estimated retention rates of 0.82 to 1.00 . All procedures followed an IACUC-approved protocol (The College of William \& Mary IACUC-2012-02-24-7720-mcfabr).

Blue catfish were supplied by a fisher who captured fish with baited hoop nets (approximately $1 \mathrm{~m}$ in diameter) that were fished in a $12-\mathrm{km}$ portion of the James River between the mouth of Upper Chippokes Creek and the mouth of the Chickahominy River (Fig. 2). The study area encompassed 3017 ha. Fish were transferred from the fisher to a net pen, which was lashed to the side of the research vessel. In 2012, we tagged and released 15,721 blue catfish with CWTs using automated CWT injectors (Mark IV tag injector; Northwest Marine Technology, Inc.); in 2013, we tagged and released 18,531 blue catfish (Table 1). Prior to tagging, fish were scanned with a handheld wand detector (Northwest Marine Technology, Inc.) to determine recapture status; fish lacking a CWT were tagged, scanned again to ensure tagging success, and released as the vessel drifted within the study area. On each day, about 50 fish were randomly selected from the net pen and measured prior to tagging; randomization was facilitated by the high turbidity such that fish within the net pen were not visible from the surface. In 2012, fish ranged in length between 214 and $464 \mathrm{~mm}$ fork length (FL; $n=899$ ); in 2013, fish ranged between 247 and $466 \mathrm{~mm}$ FL ( $n=799$; Fig. 3$)$. In both years, most of the tagged fish were $>250 \mathrm{~mm}$ FL; this size class was representative of the bulk of the blue catfish population in the James River subestuary (Fabrizio and Tuckey, unpubl. data). We used simple ANOVAs to test for annual differences in mean fish size ( $F$ statistics, least-square means) using an $\alpha$ level of 0.05 .

To monitor environmental conditions in the sampling area, we measured temperature $\left[{ }^{\circ} \mathrm{C}\right]$, salinity [psu], and dissolved oxygen $[\mathrm{mg} / \mathrm{L}]$ in surface and bottom waters on each sampling day. Additionally, we calculated monthly mean river discharge for the James River near Richmond, VA, using daily discharge data (USGS gauge 020375000) to compare freshwater flow during summer 2012 to 2014. As with fish length, we used simple ANOVAs to test for annual differences in mean environmental conditions ( $F$ statistics, $\alpha=0.05$ ).

All fish tagged in 2012 received a CWT in the right dorsal musculature; in 2013, we used multiple tag-placement locations, such that each location corresponded with a unique secondary sample (Table 2). A similar approach was used by Goulette and Lipsky (2016) to permit CWT tagging of fish and nonlethal determination of group (i.e., batch) membership. The nonlethal identification of the 2013 secondary 


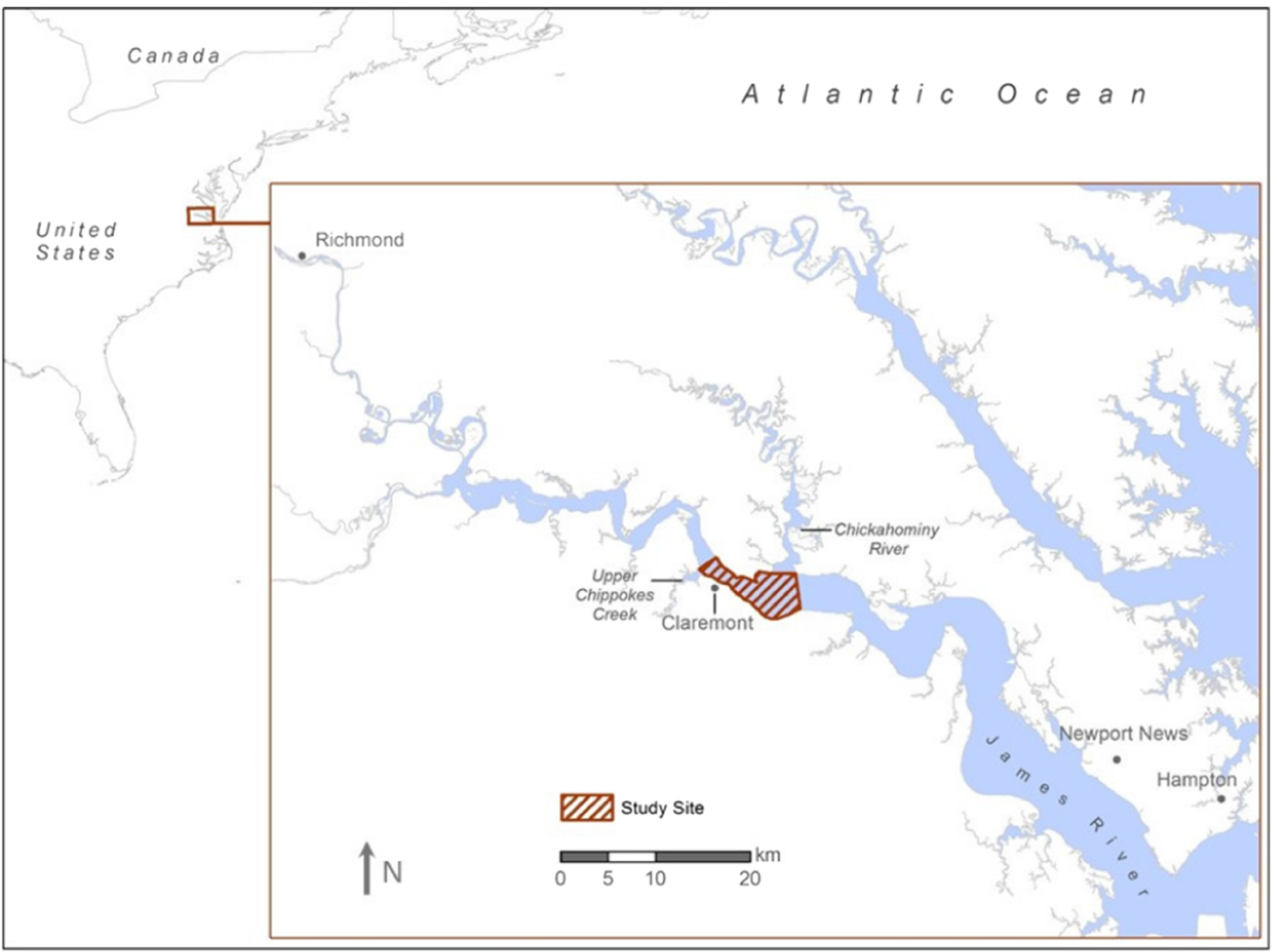

Fig. 2 Location of mark-recapture study of blue catfish in the James River subestuary, VA (red hashed area); the mouth of the James River opens to the Chesapeake Bay near Hampton, VA

sampling period allowed us to observe more than two encounter events per fish because upon recapture, the location of the tag could be used to discern tagging week.

In 2013, we recorded GPS coordinates to track the drift of the research vessel during release of tagged blue catfish in the James River; examination of drift patterns allowed us to assess the validity of the critical assumption of mixing of tagged and untagged fish. The location of drift releases varied with tide (and hence, week) but generally alternated between upriver and downriver reaches in any given week (Fig. 4). As such, released fish were well dispersed in the study area during the tagging period in 2013 and presumably well mixed with the population of untagged fish. Because the same drift-release approach was used in 2012, we believe that the mixing assumption was reasonable for both years.

\section{Live Recaptures and Dead Recoveries}

Recaptured fish were detected during tagging operations in 2012 and 2013 as noted above. Some fish that were tagged

Table 1 Summary of blue catfish tagging and inspection events by year in the James River subestuary, VA

\begin{tabular}{|c|c|c|c|c|c|c|c|c|}
\hline \multirow[t]{2}{*}{ Year } & \multicolumn{2}{|c|}{ Number of occurrences } & \multicolumn{6}{|c|}{ Number of fish } \\
\hline & Tagging & Inspection & Tagged & Inspected & Recaptured in 2012 & Recaptured in 2013 & Recovered in 2013 & Recovered in 2014 \\
\hline 2012 & 19 & 0 & 15,721 & 0 & 930 & 27 & 11 & 21 \\
\hline 2013 & 16 & 11 & 18,531 & 10,797 & - & 220 & 182 & 65 \\
\hline 2014 & 0 & 29 & 0 & 41,925 & - & - & - & - \\
\hline Total & 35 & 40 & 34,252 & 52,722 & 930 & 247 & 193 & 86 \\
\hline
\end{tabular}

An inspection event refers to the inspection of the commercial harvest for coded-wire tagged fish. Recaptures are live fish encountered during tagging operations (total $=1177$ ); recoveries are dead encounters from the harvest (total $=279$ ). The total number of recaptures and recoveries is 1456 . The total number of inspected fish was estimated by converting the daily catch to numbers using a relationship developed from 34 collections of blue catfish from the James River subestuary and valid for samples between 217 and $1409 \mathrm{lb}$ (number of fish $=64.889+1.223^{*} W$, where $W$ is in pounds; M. Fabrizio and T. Tuckey, unpubl. data) 


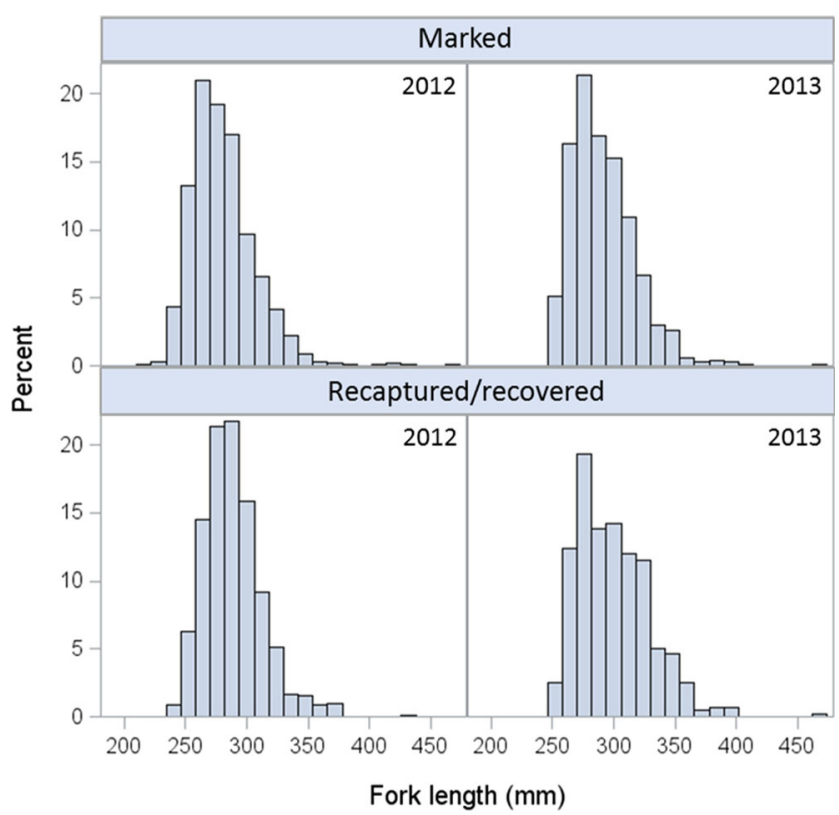

Fig. 3 Length-frequencies of blue catfish tagged and released in 2012 and 2013 in the James River subestuary, VA; only a subset of the marked fish was measured for length: 899 fish in 2012 and 799 fish in 2013 (total measured $=1698$ ). Bottom panels show length-frequencies of recaptured and recovered blue catfish measured in $2012(n=928)$ and $2013(n=435$; total $=1363$ ); only the first measurement for fish seen twice in a given week was included here

in 2012 were also recaptured in 2012 ( $n=930$ or $5.9 \%$ of the total tagged in 2012); these fish were euthanized and removed from the tagged population, and as such, were treated as "losses on capture" in the Barker Robust Design Model. Fish tagged and released in 2013 and subsequently encountered (either alive or dead) were assigned to a secondary sampling period based on the location of the CWT. Fish tagged and recaptured in 2013 were fin clipped prior to release such that the clip (upper caudal, lower caudal, or adipose) indicated the secondary period of recapture (Table 2). Thus, some fish had CWTs (in unique locations) as well as fin clips to indicate multiple recapture events.

In 2013 and 2014, we inspected the fisher's catch to recover tagged fish using an R9500 tunnel detector (Northwest Marine Technology, Inc.); 10,797 fish were scanned on
11 days in 2013 and 41,925 fish were scanned on 29 days in 2014 (Table 1). Prior to using the tunnel detector in the field, we conducted experiments in a controlled laboratory setting to determine tag-detection error rates. The falsenegative rate (i.e., failure to detect a tag) was zero, a result consistent with that reported by Vander Haegen et al. (2002). Our tag-detection experiments also indicated that falsepositive detections may occur, but these instances were rare and were readily verified by scanning with a handheld wand detector. All positive detections identified by the tunnel detector were scanned with a handheld wand to determine tag location and permit assignment of fish to the appropriate primary (2012 or 2013 releases) and secondary period (2013 releases). Daily effort (net nights), total harvest $(\mathrm{kg})$, the portion of the harvest that was inspected $(\mathrm{kg})$, the size of harvested fish (estimated from a random subsample), the number of fish recovered with CWTs, and the tag placement from recoveries were recorded during each harvest inspection. The total number of harvested fish was estimated by converting the weight of daily catches to numbers of fish using a relationship developed from 34 collections of blue catfish from the James River subestuary and valid for samples between 217 and $1409 \mathrm{lb}$ (Number of fish $=64.889+$ $1.223^{*} W$, where $W$ is in pounds; Fabrizio and Tuckey, unpubl. data). When feasible and the fisher permitted, the entire daily commercial catch was inspected in 2014 (we inspected $60.1 \%$ of the fish harvested by the fisher between 7 July and 22 August). In 2013, we inspected only a portion of the harvest (22.7\% of fish harvested between 20 July and 25 August). During inspections, a subsample of the harvest was measured; harvested fish measured 152 to $463 \mathrm{~mm} \mathrm{FL}$ $(n=525)$ in 2013 and 116 to $463 \mathrm{~mm} \mathrm{FL}(n=2850)$ in 2014.

In addition to monitoring recoveries from the commercial fishery, scientists conducting fishery-independent sampling programs in the James River scanned blue catfish for CWTs between July 2012 and December 2014 (Table 3). Electrofishing, gillnets, and bottom trawls were used during 441 sampling events to intercept 6149 blue catfish captured between mesohaline habitats at the mouth of the James River near Hampton, VA, and freshwater habitats near Richmond, VA (Fig. 2). Recoveries from
Table 2 Tag location for blue catfish marked with coded wire tags (CWTs) and released in 2012 and 2013 in the James River subestuary, VA

\begin{tabular}{lllll}
\hline Year & Secondary sampling occasion (week) & Tag 1 & Tag 2 & Fin clip (recaptures only) \\
\hline 2012 & $1-4$ & Right dorsal & - & - \\
2013 & 1 & Left dorsal & - & - \\
2013 & 2 & Left dorsal & Caudal & Upper caudal \\
2013 & 3 & Left dorsal & Right dorsal & Lower caudal \\
2013 & 4 & Caudal & - & Adipose \\
\hline
\end{tabular}

Fish tagged and released in weeks 2 and 3 of 2013 received two CWTs. Also shown are fin clip locations used in 2013 to designate recaptured fish 
Fig. 4 Release locations by week for blue catfish tagged in the James River subestuary, VA, in July-August 2013; also shown is bathymetry, with deeper areas in darker blues. Weeks refer to occasions or secondary sampling periods in the robust design. Releases occurred as the vessel drifted with the prevailing tide and currents; areas lacking releases were too shallow to allow safe maneuvering of the vessel

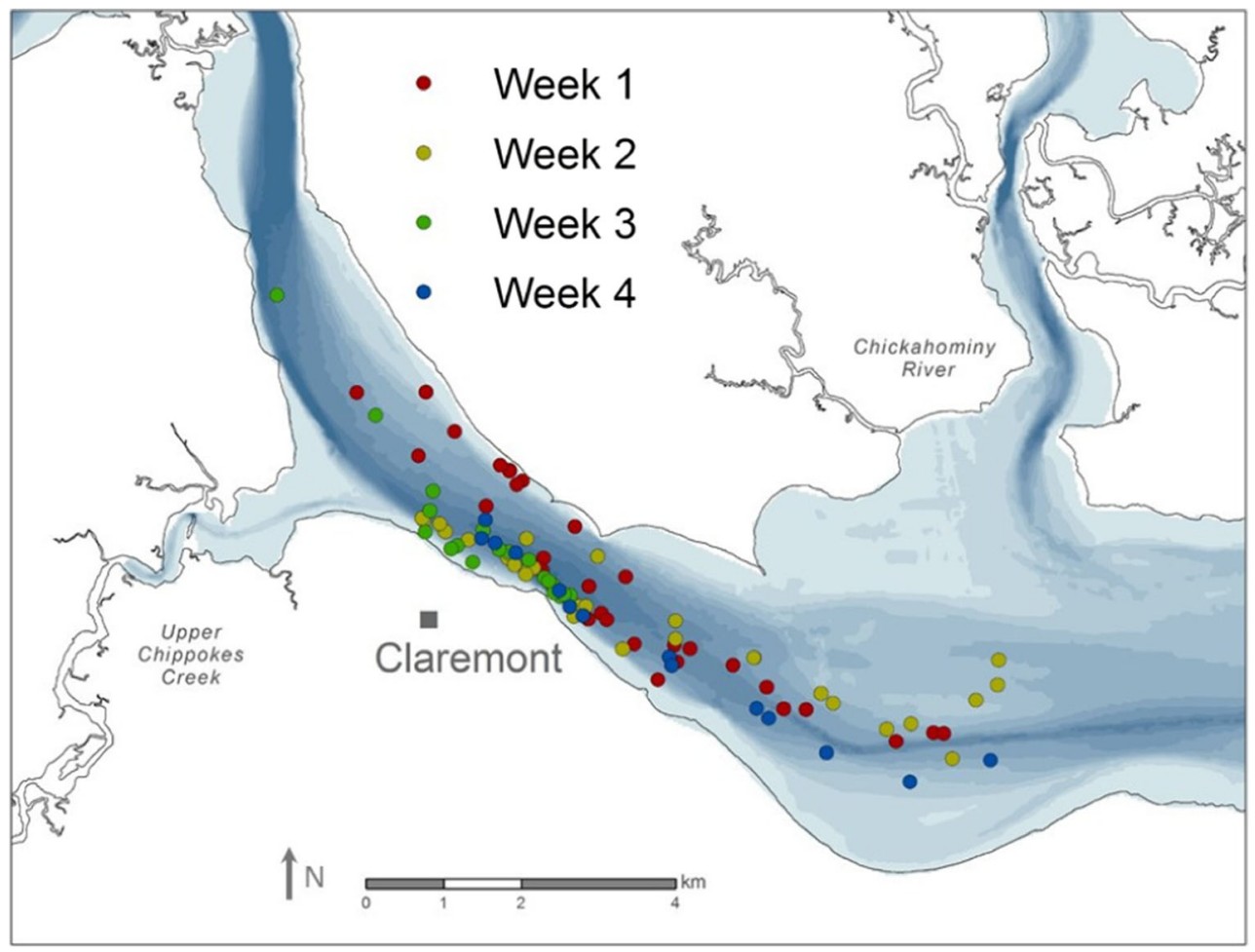

areas up- or down-estuary from our study site provided information on movement and could be used to address the closure assumption during the closed portion of the experimental design.

\section{The Barker Robust Design Model}

We fitted several models to the encounter histories for blue catfish, using Barker's modification of the robust design implemented in Program MARK (White and
Burnham 1999). The model permits estimation of detection probabilities, tag recovery rates, population size, and annual survival rates. Three types of encounters are permissible in the Barker live-dead formulation: (1) mark and release of live fish that are subsequently recaptured live; (2) dead recoveries (from the harvest); and (3) resightings, that is, tagged fish that are captured by fishers and released alive. For our study, we informed the Barker model with the first two types of encounters because resightings were not applicable. The likelihood for the Barker Robust
Table 3 Effort expended by gear and number of blue catfish inspected for coded wire tags (CWTs) in auxiliary surveys in the James River subestuary, VA, in 2012-2014

\begin{tabular}{|c|c|c|c|c|c|}
\hline Agency & Gear & $\begin{array}{l}\text { Begin } \\
\text { date }\end{array}$ & End date & $\begin{array}{l}\text { Number of sites } \\
\text { sampled }\end{array}$ & $\begin{array}{l}\text { Number of fish scanned } \\
\text { for CWTs }\end{array}$ \\
\hline VDGIF & Electrofishing & Jul 2012 & Jul 2012 & 2 & 145 \\
\hline VCU & Electrofishing & Aug 2012 & Oct 2012 & 7 & 284 \\
\hline VIMS & Trawl & Aug 2012 & Dec 2014 & 316 & 2720 \\
\hline VIMS/VDGIF & Electrofishing & Sep 2012 & Sep 2013 & 12 & 935 \\
\hline VCU/VIMS & $\begin{array}{l}\text { Electrofishing } \\
\text { and trawls }\end{array}$ & Oct 2012 & Oct 2012 & 12 & 321 \\
\hline VA Tech & Electrofishing & May 2013 & Jun 2013 & 14 & 658 \\
\hline VIMS & Gill net & Mar 2014 & May 2014 & 78 & 1086 \\
\hline TOTAL & & & & 441 & 6149 \\
\hline
\end{tabular}

The VIMS/VDGIF survey occurred only in September of each year; the VIMS trawl survey occurred monthly. Surveys spanned the area from Richmond, VA, to the James River Bridge near Newport News, VA. All fish $\geq 240 \mathrm{~mm}$ FL were scanned for CWTs. Number of sites sampled are individual locations (electrofishing transects or trawl tows) or number of sets (gill net)

VCU Virginia Commonwealth University, VDGIF Virginia Department of Game and Inland Fisheries, VIMS Virginia Institute of Marine Science, VA Tech Virginia Polytechnic Institute and State University 
Design Model comprises three parts: (1) the closedcaptures portion for estimating population size and detection probabilities, (2) the Cormack-Jolly-Seber (CJS) portion from live recaptures, and (3) the dead recovery portion from dead recoveries. The closed period occurred in 2013 (with multiple secondary occasions); thus, fish tagged in 2013 and recaptured in 2013 provided information on population size at the beginning of 2013. The 2012 releases and recaptures were used to estimate survival rates using the open-population CJS model estimators.

In this design, dead encounters (recoveries) are assumed to occur in the interval between primary sampling periods. The robust design assumption of closure during the secondary occasions is violated when fish are removed by harvesting (which occurred in 2013). However, because the estimated population size is the size on the first sampling occasion in 2013, these removals lead to individual heterogeneity in the detection probabilities but do not directly affect the estimate of population size. Fish removed (harvested) during the closed secondary occasions in 2013 had their probability of live capture set to zero in subsequent secondary occasions.

The closed-captures portion of the likelihood for the Barker Robust Design Model is joined to the CJS likelihood via the detection probabilities, $p$. That is, the CJS likelihood estimates the probability of a fish being detected one or more times during the secondary occasions within a primary occasion; this probability is denoted as $p^{*}$ in robust design models. The closed-captures initial detection probabilities relate to $p^{*}$ as

$p^{*}=1-\prod_{t}\left(1-p_{t}\right)$.

That is, the product of $1-p_{t}$. values is the probability of never encountering a fish during the secondary occasions, so that one minus this product $\left(p^{*}\right)$ is the probability of encountering a fish one or more times during the primary occasion. Thus, the $p_{t}$ parameters in the closed-captures likelihood are also influenced by the CJS detection probabilities via $p *$. The CJS portion of the likelihood is joined to the dead recoveries portion of the likelihood via the annual survival rates, $S$.

Population size, $N$, is computed as a derived parameter based on the closed-captures portion of the likelihood, using the Huggins $(1989,1991)$ and Alho (1990) approaches. Effectively, the number of unique fish seen one or more times (commonly denoted as $M_{t+1}$ ) is divided by the probability of being observed one or more times to estimate population size:

$\hat{N}={ }^{M_{t+1}} /{ }_{1-} \prod_{t}\left(1-p_{t}\right)$.

The Huggins estimator was extended to include individual heterogeneity (White and Cooch 2017), so that now, the probability of capturing each individual is summed across the individuals captured. Because we did not have multiple secondary occasions during 2012 and 2014, population sizes could not be estimated for these primary sessions.

Confidence intervals for probabilities $S, r$, and $p$ were computed with a logit transformation, where $\operatorname{logit}(\theta)=\log [\theta /(1-\theta)]$ and $\theta=S, r$, or $p$; here, $S$ is the annual survival probability, $r$ is the probability that a tag is recovered given that the fish has died, and $p$ is the detection probability of untagged fish (see Table 4 for description of these parameters). Confidence intervals for $S, r$, and $p$ were computed on the logit scale and then transformed back to the original scale.

Confidence intervals for $N$ were computed assuming a lognormal distribution on the number of animals never captured $\left(f_{0}\right)$, with $\hat{N}=\hat{f}_{0}+M_{t+1}$, where $M_{t+1}$ is the number of animals captured at least once during the primary period. The following equations describe the procedure:

$$
\begin{gathered}
\hat{f}_{0}=\hat{N}-M_{t+1} \\
\mathrm{LCI}=\hat{f}_{0} / C+M_{t+1}, \\
\mathrm{UCI}=\hat{f}_{0} C+M_{t+1}, \text { and } \\
C=\exp \left\{1.96 \times \sqrt{\log _{e}\left[1+\left(\frac{S E\left(\hat{f}_{0}\right)}{\hat{f}_{0}}\right)^{2}\right]}\right\} .
\end{gathered}
$$

Models Considered We allowed the $S$ and $r$ parameters of the Barker Robust Design to vary with year and the $p$ parameters to vary with sampling occasion; however, some parameters were fixed because they could not be estimated from the data. In particular, detection probability $p$ for the 2012 primary occasion was fixed to one because this parameter was not identifiable from the single secondary occasion; we note that fixing this parameter to one does not affect the CJS portion of the likelihood nor the dead recoveries portion of the likelihood because $p$ for 2012 is not included in these parts of the likelihood. The $p$ values (probability of detecting fish alive) for the 2014 primary session were fixed to zero; here, no live fish were captured in 2014, so the probability of detection (of live fish) in 2014 was actually zero. Fidelity, the probability of remaining in the study area, was fixed to one because with the exception of a single fish, no tagged fish were encountered outside of our study area (see the "Results" section). Recapture probabilities were assumed equal to initial capture probabilities in all cases.

Because live encounters did not occur in 2014, and because no releases occurred in 2014, the survival estimate for 2013 was confounded with the inestimable $p^{*}$ value for 2014 and the estimate of survival for 2014 . Further, the survival rate for 2014 was confounded with the recovery rate, $r$, for 2014 , and thus, only the product, 
Table 4 Parameters of the Barker Robust Design Model used to estimate population size, survival rates, detection probabilities, and tag recovery rates for blue catfish in the James River subestuary, VA, 2012-2014

\begin{tabular}{|c|c|}
\hline Model parameter & Description \\
\hline$S_{\text {year }}$ & Annual survival between primary sessions, with one additional survival rate estimated post- 2014 . \\
\hline$p_{\text {year*occasion }}$ & $\begin{array}{l}\text { Detection probability of untagged fish during each secondary occasion in } 2013 . \\
\text { The detection probability for } 2012 \text { is not identifiable from the closed-capture } \\
\text { portion of the likelihood because there is only one secondary occasion, and this } \\
\text { parameter is not part of the Cormack-Jolly-Seber or dead recoveries portion of the likelihood. } \\
\text { To allow us to use the } 2012 \text { releases for estimation of survival, we fixed the first } p \text { parameter } \\
\text { in } 2012 \text { to one, conditioning on capture during } 2012 \text { and indicating that the captured fish were } \\
\text { released. Four } p \text { parameters were estimated for the } 2013 \text { secondary occasions based on the closed-captures model. } \\
\text { The } p \text { parameter was fixed to zero for the dummy secondary occasion in } 2012 \text {, and also for } \\
\text { the two dummy secondary occasions in } 2014 \text {. Note that all the models considered assumed } \\
\text { that } p=c \text {, i.e., that initial detection probabilities }(p) \text { were the same as recapture probabilities }(c) \text {. } \\
\text { Thus, for these models, } p \text { is the probability of capturing a fish regardless of whether it had been previously tagged. }\end{array}$ \\
\hline$c_{\text {year*occasion }}$ & $\begin{array}{l}\text { Probability of capturing (recapturing) a tagged fish that was marked during the same primary occasion. } \\
\text { Only three recapture probabilities during } 2013 \text { are estimable, and all the models assumed that } c=p \text {, i.e., } \\
\text { that recapture probabilities }(c) \text { were the same as initial detection probabilities }(p) \text {. }\end{array}$ \\
\hline$r_{\text {year }}$ & Probability that the tag is recovered given that a fish has died. \\
\hline$R_{\text {year }}$ & $\begin{array}{l}\text { Probability that a fish is encountered alive between primary occasions and remains alive } \\
\text { to the next primary occasion. All } R \text { parameters were fixed to zero. }\end{array}$ \\
\hline$R_{\text {year }}^{\prime}$ & $\begin{array}{l}\text { Probability that a fish is encountered alive between primary occasions but dies before the next primary occasion. } \\
\text { All } R^{\prime} \text { parameters were fixed to zero. }\end{array}$ \\
\hline$F_{\text {year }}$ & $\begin{array}{l}\text { Fidelity of fish to the study area between primary sessions. These parameters were fixed } \\
\text { to one because they are not estimable. }\end{array}$ \\
\hline$a_{\text {year }}^{\prime}$ & $\begin{array}{l}\text { Probability of a fish remaining in the study area between primary sessions. } \\
\text { These parameters were fixed to one because they are not estimable. }\end{array}$ \\
\hline$a_{\text {year }}^{\prime \prime}$ & $\begin{array}{l}\text { Probability that a fish that has temporarily emigrated from the study area between primary sessions } \\
\text { has returned to the study area. These parameters were fixed to one because they are not estimable. }\end{array}$ \\
\hline
\end{tabular}

$S(1-r)$, was estimable. Out of the possible three $S$ and three $r$ parameters, only four quantities are estimable because no newly tagged fish were released in 2014. Therefore, three models for $S$ and $r$ were considered with various constraints:

S.r.

S.r. $r_{2012,2013=2014}$ and

$\mathrm{S}_{2012,2013=2014} \mathrm{r}_{2012,2013=2014}$.

The notation "2012, $2013=2014$ " denotes that the parameter for the first year (2012) was estimated separately, and parameters for 2013 and 2014 were set equal. The motivation for fixing the last 2 years for $S$ or $r$ was that the harvest rates or the inspection of harvested fish were similar for 2013 and 2014 , whereas these values were different for 2012, when no harvested fish were inspected.

We considered multiple models for detection probabilities $p$ in 2013. The first model estimated a separate $p$ for each secondary session — denoted $p_{\text {secondary session, }}$ the second model specified $p$ as a constant across secondary sessions-denoted $p$. To account for individual heterogeneity in detection probabilities, an extension of the $p_{\text {secondary session }}$ model following White and Cooch (2017) was considered where a random effect was added to $\operatorname{logit}(p)$ on the logit scale for each individual, i.e.,

$$
p_{i}=\frac{1}{1+\exp \left(-\left[\operatorname{logit}(\bar{p})+z_{i}\right]\right)},
$$

where $z_{i}$ is a normally distributed random variable with mean zero and standard deviation $\sigma_{\mathrm{p}}$ associated with fish $i$. The likelihood was integrated numerically over the normal distribution so that $\sigma_{\mathrm{p}}$ could be estimated. Another model for $p$ included the effect of fishing effort, which was measured as net nights in each of the 2013 secondary occasions. Effort ranged from a high of 168 net nights in week 1 to 113 net nights in week 4 . The use of effort as a covariate allowed time variation in $p$ but was different from $p_{\text {secondary session. The }}$ individual random effects model was also considered with the effort models. Model selection was based on quasi-AIC (due to the adjustment for overdispersion, see below), which was corrected for small sample sizes. 
Overdispersion and Model fit The confounding of the $S$ and $r$ parameters precluded evaluation of model fit for the openpopulation portion of the model. However, due to individual heterogeneity in detection probabilities and the possible lack of independence among captures, extra-binomial variation may exist within the closed-captures portion. Although the logit normal model described above provided strong evidence of individual heterogeneity (see the "Results" section), we considered the possibility that additional extra-binomial variation may be present. Therefore, we used the median $\hat{c}$ procedure in MARK to assess the extent of overdispersion in the closed-captures portion of the likelihood (Cooch and White 2016). Here, we used the encounter histories for the 2013 live captures applied to the model that included individual random effects to estimate median $\hat{c}$. We generated three estimates of $\hat{c}$ $(1.46,1.48$, and 1.50$)$ and assessed the extra-binomial variation using Monte Carlo methods; logistic regression was used to estimate the median value. The mean and median value of $\hat{c}$ was 1.48 (standard error of the mean $=0.013$ ). This estimate of $\hat{c}$ was applied to the full Barker Robust Design Model.

\section{Results}

\section{Environmental Conditions}

Compared with 2012, average environmental conditions in surface and bottom waters in 2013 were significantly cooler $\left(F_{\text {surface }}=44.08, P<0.01 ; F_{\text {bottom }}=50.20, P<0.01\right)$, fresher $\left(F_{\text {surface }}=108.76, P<0.01 ; F_{\text {bottom }}=75.15, P<0.01\right)$, and more oxygenated $\left(F_{\text {surface }}=15.54, P<0.01 ; F_{\text {bottom }}=44.71\right.$, $P<0.01)$. Although we noted significant inter-annual differences, these differences were relatively small: mean surface conditions were $30.5{ }^{\circ} \mathrm{C}(\mathrm{SE}=0.123)$ and $0.7 \mathrm{psu}$ $(\mathrm{SE}=0.048)$ in 2012 and $28.8^{\circ} \mathrm{C}(\mathrm{SE}=0.256)$ and $0.1 \mathrm{psu}$ $(\mathrm{SE}=0)$ in 2013; mean bottom conditions were $29.8^{\circ} \mathrm{C}$ $(\mathrm{SE}=0.080)$ and $0.9 \mathrm{psu}(\mathrm{SE}=0.077)$ in 2012 and $28.2^{\circ} \mathrm{C}$ $(\mathrm{SE}=0.266)$ and $0.1 \mathrm{psu}(\mathrm{SE}=0.010)$ in 2013. Lower temperatures and salinities in 2013 reflected the higher mean discharge in summer in the James River in that year (Fig. 5). Dissolved oxygen conditions in our study area exceeded $3.3 \mathrm{mg} / \mathrm{L}$ in summer 2012 and 2013, a pattern consistent with historically observed conditions in the James River (Tuckey and Fabrizio 2016a).

\section{Tagged, Recaptured, and Recovered Fish}

Fish marked and released in 2013 were, on average, $10.4 \mathrm{~mm}$ larger than those marked and released in 2012 $\left(\operatorname{mean}_{2012}=280.2 \mathrm{~mm} \mathrm{FL}, \mathrm{SE}_{2012}=0.896, n_{2012}=899\right.$; mean $\left._{2013}=290.6 \mathrm{~mm} \mathrm{FL}, \mathrm{SE}_{2013}=0.924 ; n_{2013}=799\right)$. Although statistically significant $(F=65.37, P<0.01)$, the 10.4-mm greater size observed in 2013 is not likely to be

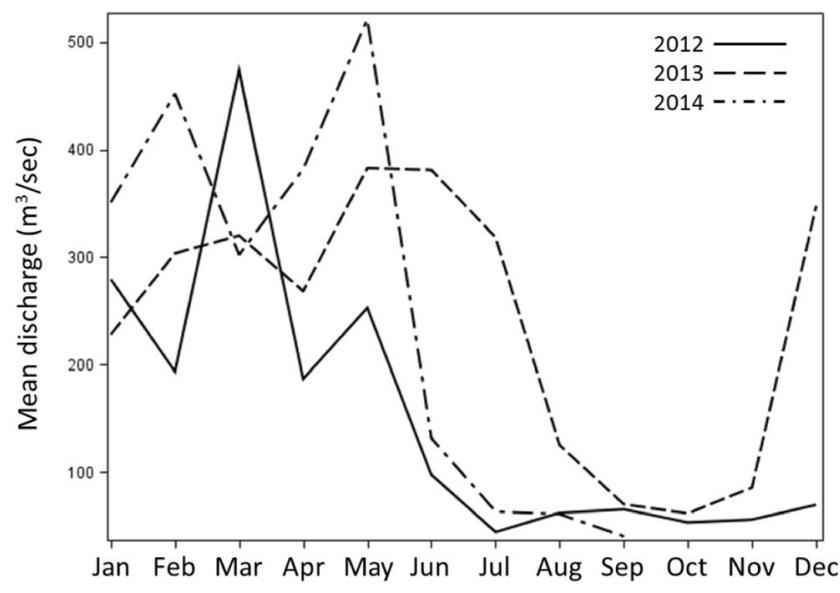

Fig. 5 Mean monthly discharge $\left(\mathrm{m}^{3} / \mathrm{s}\right)$ for the James River, VA, in 2012, 2013, and 2014. Data are from USGS gauge 02037500 near Richmond, VA

biologically significant given the broad size range of fish that were tagged (Fig. 3).

We observed 247 recaptures during 2013 that ranged in size from 253 to $398 \mathrm{~mm}$ FL (mean $=301.8 ; \mathrm{SE}=1.820$; $n=245$ ). Fish tagged in 2012 and recaptured in 2013 $(n=27)$ represented a relatively small proportion of the total recaptures in that year $(10.9 \%)$, and the majority $(89.1 \%)$ of fish recaptured in 2013 were tagged in 2013 (Table 1). As expected, most of the 2013 releases that were recaptured in 2013 were fish that were released in weeks $1(48.8 \%)$ and 2 $(37.8 \%)$. The majority $(98.2 \%)$ of 2013 releases that were recaptured had no fin clip, indicating they were first-time recaptures, and no fish was recaptured more than twice after initial release.

Fish recovered from the 2013 harvest $(n=193)$ ranged in size from 246 to $462 \mathrm{~mm}$ FL (mean $=295.6 \mathrm{~mm} \mathrm{FL}$, $\mathrm{SE}=2.195$ ), whereas substantially smaller fish were present in the unmarked portion of the harvest in $2013(152-463 \mathrm{~mm}$ FL; mean $=260.9 \mathrm{~mm}$ FL, SE $=1.459$ ). Fish tagged in 2012 comprised a relatively small proportion (5.7\%) of the 2013 recoveries. Similar to recaptures, fish tagged in weeks 1 (34.7\%) and $2(40.4 \%)$ in 2013 comprised the majority of recoveries in 2013.

We detected and recovered only 86 tagged fish (272$483 \mathrm{~mm}$ FL; mean $=333.2 \mathrm{~mm}$ FL, $\mathrm{SE}=5.108$ ) from among 41,925 fish harvested in 2014 (Table 1). Low recovery rates observed in 2014 were consistent with the lower overall fishing effort that occurred in July-August of that year (effort $_{2013}=1324$ net nights; effort $_{2014}=1052$ net nights). The mean size of fish harvested in 2014 was $242.2 \mathrm{~mm} \mathrm{FL}$ ( $n=2849)$, which was significantly less than the mean size of fish harvested in 2013 (260.9 mm FL; $n=525 ; F=82.14$, $P<0.01$ ). The majority (75.6\%) of 2014 recoveries was comprised of fish released in 2013.

Despite incorporating multiple gear types and sampling diverse habitats (within, up-estuary, and down-estuary of 
the study site in the James River subestuary), only one coded-wire tagged blue catfish was encountered by auxiliary surveys in 2012-2014 (Table 3). The VIMS Juvenile Fish Trawl Survey, which operated monthly and yearround within and down-estuary of the study area, intercepted the tagged fish, which was tagged and released in 2012 and recovered on 26 April 2014, about $26 \mathrm{~km}$ down-estuary of the lower boundary of our tagging area. The extremely low recovery rate was surprising because electrofishing, gill nets, and trawls are highly effective at capturing blue catfish in tidal waters. The lack of additional recoveries by electrofishing and trawl surveys was unanticipated because these surveys in particular occurred within our 12-km study area.

\section{Survival Rates and Population Size}

The Barker Robust Design Model that was most empirically supported by the blue catfish data included nine parameters and allowed survival, recovery, and detection rates to vary by sampling event and with random effects (Table 5). Simple models with only five to seven parameters were poorly supported (Table 5). All models accounted for extra-binomial variation using the median $\hat{c}$ estimate of 1.48 , with a standard error of 0.013 . Nearly all of the model weight $(99.3 \%)$ was associated with the model $S_{2012,2013=2014} r_{2012,2013=2014} p_{2013-}$ *secondary,random effects (Table 5). Therefore, we did not consider model averaging.

The selected model included the following estimated parameters: $S_{2012}, S_{2013=2014}, r_{2012}, r_{2013=2014}, \sigma_{p}, p_{2013 \text {,occl }}$, $p_{2013, o c c 2}, p_{2013, o c c 3}, p_{2013, o c c 4}$, where $\sigma_{p}$ is the standard deviation of the random effect on $p$, and "occ" refers to the secondary sampling occasion (Table 6). The estimated annual apparent survival rate in 2012 was $0.16(\mathrm{SE}=0.035)$, with a $95 \%$ confidence interval of 0.10 to 0.24 . The estimated survival rate in 2013 and 2014 was significantly greater: 0.44
( $\mathrm{SE}=0.070)$, with a $95 \%$ confidence interval of 0.31 to 0.58 . These are apparent rates because fish likely emigrated from the study area, thereby contributing to "losses." The single estimate of recovery rate for dead fish, which applies to 2013 and 2014 , was relatively low $(0.02, \mathrm{SE}=0.002)$, but differed from zero. The probability of detecting an untagged fish during each of the four secondary occasions in 2013 varied and was quite low, $0.0010-0.0022$; although these probabilities were not significantly different, the point estimates declined monotonically with time. Additionally, the model suggests that detection probabilities in 2013 exhibited individual heterogeneity which could be described with a normal distribution on the logit scale (random effects). The estimate of $\sigma_{p}$ which is a measure of the individual heterogeneity in detection probabilities, was high, $1.05(\mathrm{SE}=0.16)$, suggesting large variation in the probability of detection among individual fish.

The population estimate for the 2013 closed-captures primary occasion was $\hat{N}=1,639,830$ with a standard error of 403,156 and $95 \%$ confidence interval of 1,021,680-2,638,900 when not corrected for overdispersion. When corrected, the standard error was 490,460 and the $95 \%$ confidence interval was $926,307-2,914,208$.

\section{Discussion}

Our results provide the first estimate of population size for invasive blue catfish in the Chesapeake Bay region. In JulyAugust 2013, tidal habitats along a 12-km stretch of the James River near Claremont, VA, supported about 1.6 million invasive blue catfish ( $95 \%$ CI 0.9 to 2.9 million), or about 544 blue catfish/ha. This estimate is consistent with high catch rates observed from electrofishing (Greenlee and Lim 2011) and bottom-trawl (Fabrizio and Tuckey, pers. obs.) surveys in this section of the James River. The population size estimate applies

Table 5 Model selection results for blue catfish using the Barker Robust Design in Program MARK

\begin{tabular}{lllll}
\hline Model & QAIC $_{\mathrm{c}}$ & $\Delta$ QAIC $_{\mathrm{c}}$ & QAIC Weight & $k$ \\
\hline$S_{2012,2013=2014} r_{2012,2013=2014} p_{2013} *_{\text {secondary, random effects }}$ & $38,016.036$ & 0 & 0.9927 & 9 \\
$S_{2012,2013=2014} r_{2012,2013=2014} p_{2013} *_{\text {secondary }}$ & $38,025.860$ & 9.824 & 0.0073 & $56,237.09$ \\
$S_{0} r_{2012,2013=2014} p_{2013 * \text { secondary }}$ & $38,072.828$ & 56.792 & 0 & $56,254.59$ \\
$S_{2012,2013=2014} r_{2012,2013=2014} p_{2013}$ effort, random effects & $38,202.295$ & 186.259 & 0 & $76,327.06$ \\
$S_{2012,2013=2014} r_{2012,2013=2014} p_{2013}$ effort & $38,212.057$ & 196.021 & 0 & $56,518.67$ \\
$S . r \cdot p_{2013} *_{\text {secondary }}$ & $38,244.681$ & 228.645 & 0 & $56,536.08$ \\
$S_{2012,2013=2014} r_{2012,2013=2014} p_{2013}$ constant, random effects & $39,070.086$ & 1054.050 & 0 & $56,584.36$ \\
$S_{2012,2013=2014} r_{2012,2013=2014} p_{2013 \text { constant }}$ & $39,079.331$ & 1063.295 & 0 & $57,805.96$ \\
\hline
\end{tabular}

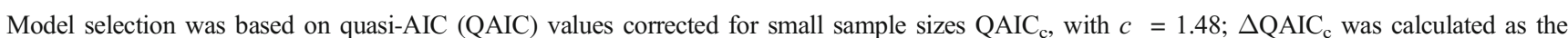
difference in the $\mathrm{QAIC}_{\mathrm{c}}$ values of the candidate model and the model with the lowest $\mathrm{QAIC}_{\mathrm{c}}$. The number of parameters is $k$; $S, r$, and $p$ are defined in Table 4; a $\operatorname{dot}(\bullet)$ in the subscript denotes a constant rate, "2013*secondary" indicates that $p$ varied with secondary occasion in 2013 , "random effects" indicates random effects on $p$, and "2013 effort" indicates that $p$ varies with fishing effort 
Table 6 Parameter estimates from the minimum $\mathrm{QAIC}_{c}$ model, $S_{2012,2013=2014} r_{2012,2013=2014} p_{2013}{ }^{*}$ secondary, random effects

\begin{tabular}{lllll}
\hline Parameter & Estimate & SE & \multicolumn{2}{l}{ Logit-based CI } \\
\cline { 3 - 5 } & & & LCI & UCI \\
\hline$S_{2012-2013}$ & 0.16164 & 0.03528 & 0.10374 & 0.24310 \\
$S_{2013-2014 \& \text { 2014-2015 }}$ & 0.44330 & 0.06987 & 0.31375 & 0.58106 \\
$r_{2012}$ & 0 & 0 & 0 & 0 \\
$r_{2013=2014}$ & 0.01667 & 0.00181 & 0.01347 & 0.02061 \\
$\sigma_{p(2013)}$ & 1.05122 & 0.15515 & 0.74712 & 1.35532 \\
Median $p_{2013 \text { Occasion 1 }}$ & 0.00223 & 0.00102 & 0.00091 & 0.00545 \\
Median $p_{2013}$ Occasion 2 & 0.00200 & 0.00092 & 0.00082 & 0.00490 \\
Median $p_{2013 \text { Occasion 3 }}$ & 0.00140 & 0.00064 & 0.00057 & 0.00343 \\
Median $p_{2013}$ Occasion 4 & 0.00103 & 0.00047 & 0.00042 & 0.00253 \\
\hline
\end{tabular}

Standard errors and confidence intervals are corrected for overdispersion with $c=1.48$. Logit-based confidence intervals (CIs) used the logit transformation to produce the lower (LCI) and upper (UCI) $95 \%$ bounds

to the portion of the blue catfish population that ranges in size from 240 to $460 \mathrm{~mm}$ FL and which is vulnerable to capture by the commercial hoop-net fishery. These same size classes are commonly observed in bottom trawl surveys (Tuckey and Fabrizio 2016b) and electrofishing surveys (Greenlee and Lim 2011), and as such likely represent a considerable portion of the total biomass of blue catfish in the tidal James River. Some of the tagged fish in our study were $>300 \mathrm{~mm}$ FL, which is the size at which individuals begin to include fishes in their $\operatorname{diet}$ (Schloesser et al. 2011; Schmitt et al. 2017). Fish > 300 mm FL are also typically observed at the leading edge of the range of distribution of this species in Chesapeake Bay subestuaries (Fabrizio and Tuckey, unpubl. data), and these fish are likely to participate in colonization of estuarine habitats. Further, we note that blue catfish occupy habitats throughout the James River from non-tidal freshwater areas to the mouth of the James River subestuary near Hampton, VA. Although density estimates of blue catfish are unknown in up-estuary or downestuary areas from our study site, observations from fishery surveys suggest relative abundance declines down-estuary as salinity increases and annual abundances can fluctuate widely (Tuckey and Fabrizio 2016b).

The estimate of the population size depends on estimates of $p$, the probability of detection, and in this study, median estimates of $p$ were $\leq 0.0022$. These are extremely low values and may not produce a precise estimate of population size (White and Cooch 2017), particularly given the high degree of heterogeneity among individuals (as estimated by $\sigma_{\mathrm{p}}$ ). We observed declining probabilities of detection (i.e., $p$ ) in 2013, which mirrored the pattern in fishing effort. However, the decline in $p$ was not significant, possibly because of the large amount of heterogeneity in $p$ among individual fish. In addition, we found no evidence of heterogeneity in $p$ associated with fish size: the range of sizes of recaptured fish was similar to the range of sizes of marked fish in the James River (Fig. 3). Thus, size-based movement was not likely occurring in this population during July-August 2013.

Proper inference from tagging studies requires acknowledgement of assumptions (Burnham et al. (1987) and in this study, the following assumptions apply: (1) marked fish are representative of the population of fish about which one seeks mortality information; (2) initial handling, marking, and holding do not affect survival rate; (3) the numbers of fish released are exactly known; (4) all releases and recaptures occur in brief time intervals, and recaptured fish are released immediately; (5) marking (tagging) is accurate and no marks (tags) are lost or misread; (6) the fate of each fish, after any known release, is independent of the fate of any other fish; (7) with multiple lots (or other replication), the data are statistically independent over lots; (8) statistical analyses of the data are based on the correct model; (9) captured fish that are rereleased have the same subsequent survival and capture rates as fish alive at that site which were not caught, i.e., capture and rerelease do not affect their subsequent survival or recapture; and (10) all fish (in the study) of an identifiable class (e.g., size or replicate) have the same survival and capture probabilities; this is an assumption of parameter homogeneity. Assumptions 1 to 4 relate to study planning, field procedures, and generality of the desired inferences; these assumptions are reasonable given the study design and the manner in which we implemented the study in the field. The effect of tag loss (assumption 5) is to bias survival estimates low (Arnason and Mills 1981; Pollock 1981) and to decrease precision of survival rate estimates from CJS models (Arnason and Mills 1981); in the presence of non-negligible tag loss, survival rates are adjusted using estimates of tag loss (e.g., Fabrizio et al. 1997; Pollock et al. 2007). Tag loss also results in estimates of population size that are biased low and less precise than estimated. Laboratory evidence for tag loss suggests such rates are low or negligible; therefore, we did not adjust our estimates of survival or population size. Assumptions 6 and 7 relate to the stochastic component of the models, and assumptions 8 to 10 relate to model structure. We used the median $\hat{c}$ procedure to correct for overdispersion, including individual heterogeneity (assumption 10) and possible lack of independence of tags (assumption 6).

Additionally, one of the key assumptions of the robust design is that the population remains closed during the secondary periods; in our case, this implies that fish remained in the study area during the multi-week secondary occasions in 2013 and the population experienced no significant additions or deletions. If fish emigrated permanently from the area or if fish colonized our study area from adjacent habitats in the James River, or from nearby tributaries such as the Chickahominy River or Upper Chippokes Creek (Fig. 2), then our estimate of population size is biased high. We conducted our sampling during a time when long-range movements of 
blue catfish were thought to be minimal based on a telemetry study conducted in their native range (i.e., post-spawning, in summer; Garrett and Rabeni 2011). Habitat conditions in our study area in 2013 were fresher and cooler than in 2012, which may have decreased the likelihood of permanent emigration of fish out of our study area, although we note that the effects of environmental conditions on invasive blue catfish movements are unknown. In general, the movement ecology of blue catfish within the James River system is largely unexplored. Blue catfish may have moved from the study area to tributaries of the James River such as the Chickahominy River or Upper Chippokes Creek and remained there for extended periods of time (e.g., greater than 1 month); in this manner, fish may have been unavailable for capture, thereby violating the closure assumption. Because these and other tributaries of the James River subestuary are not routinely surveyed for blue catfish by existing fishery programs, we were unable to assess the likelihood of these movements. Such movement corridors are thought to be important in sustaining ephemeral populations of freshwater fishes in estuarine environments by permitting colonization of individuals from freshwater populations (Adams and Wolfe 2007). Although the blue catfish population in this portion of the tidal James River is not ephemeral (Tuckey and Fabrizio 2016b), colonization of estuarine habitats by individuals that reside primarily in tributaries may occur. The hypothesis that individual blue catfish are resident year-round in estuarine waters has not been explored, nor do we know the degree of connectivity between tributary populations and those in the James River subestuary. A better understanding of habitat use and movement of invasive blue catfish in the Chesapeake Bay region is warranted and could help elucidate population structure and identification of appropriate management units. Such information could also be used to identify and delineate subpopulations for further control.

In addition to movement of blue catfish into or out of the study area during the putative closed period, removals due to the fishery may also violate the closure assumption. Fishery removals during the secondary occasions of 2013 are a potentially large source of uncertainty, and if removals are nonnegligible, the closure assumption will be invalid. In this case, our estimate of population size would be biased high. Although we did not inspect the entire harvest for removals on each of the 2013 secondary occasions, we did account for known removals during those times.

In contrast to the effect of fishery removals on estimates of population size, the CJS estimates of survival rates are not likely to be affected by fishery removals because the population is "open" to losses. Thus, the higher apparent survival rates observed in 2013-2014 relative to 2012-2013 suggest that a greater proportion of fish occupied the study area in 20132014. Greater occupancy in the area may reflect a lack of permanent emigration, higher actual survival rates, or both. Significant movement of blue catfish away from the study area was not detected despite surveillance by auxiliary fishery sampling programs: we observed an extremely low recovery rate $(0.02 \%)$ of blue catfish from among more than 6000 fish scanned for CWTs from the freshwater to the mesohaline habitats of the James River. Surveys for tagged blue catfish occurred year round, with multiple (and highly effective) gears, from broad spatial areas that included and extended beyond our study site, yet only a single tagged fish was encountered. This result may be obtained if movement of blue catfish within the James River subestuary was minimal, if population size was extremely high, or both. We note that blue catfish in Chesapeake Bay subestuaries may undertake extensive longdistance movements Tuckey et al. (in review). Thus, the higher survival rates estimated in 2013-2014 relative to the previous year likely reflect higher apparent survival of fish (decreased losses from the population) and are consistent with a large population of blue catfish in this portion of the tidal James River.

One of the motivating questions for this study concerned the level of removal (e.g., harvest) required to reduce the density of blue catfish populations in tributaries of Chesapeake Bay. The feasibility and efficacy of using blue catfish fishery removals to reduce abundance in coastal tributaries is not known. An estimate of the amount of surplus production associated with each stock and the harvest level that can be sustained is needed to assess the likelihood that removals due to the fishery will be effective in controlling the spread of this invasive species. In addition, we currently lack knowledge of how and when individuals colonize estuarine environments and factors associated with the down-estuary range expansions observed in coastal tributaries. Changes in spatially explicit abundances have been postulated to be associated with environmental factors; in particular, river flow and precipitation in the watershed are thought to affect blue catfish movements and range expansion in tidal tributaries of Chesapeake Bay (Edmonds 2006). Further research could help to understand habitat use and the magnitude of fish movement; in particular, examination of the partial migration strategy (e.g., Jonsson and Jonsson 1993; Kerr et al. 2009) for this species could elucidate the role of movement in maintaining population abundance and in realizing range expansion.

Acknowledgements We thank R. Neal Leatherwood for providing the fish for this study, Northwest Marine Technology for loaning us the R9500 tunnel detector, Chris Bonzek (Virginia Institute of Marine Science, VIMS) for database management support, and Deb Gauthier (VIMS) for assistance with the figures. We are grateful to the scientists who scanned catches for tagged blue catfish: Patrick McGrath (VIMS); Joseph Schmitt (Virginia Tech); Greg Garman and Steve McIninch (Virginia Commonwealth University); Eric Brittle, Aaron Bunch, and Bob Greenlee (Virginia Department of Game \& Inland Fisheries); and Hank Brooks, Aimee Comer, Christopher Davis, Rebecca Hailey, James Harrison, Jennifer Greaney, Emily Loose, and Wendy Lowery (VIMS Juvenile Fish Trawl Survey). Finally, we thank Shirley Chu, Beth Dzula, Sayer Fisher, Drew Friedrichs, Ben Lanning, Christi Linardich, 
Sarah N. Mahlandt, Matt Oliver, Manisha Pant, Carol Paulson, and Dominique Thomas for their assistance in the field, along with numerous VIMS staff, students, and volunteers who also helped. Two anonymous reviewers provided helpful comments on an earlier version of this manuscript. This paper is Contribution No. 3656 of the Virginia Institute of Marine Science, The College of William \& Mary.

\section{Compliance with Ethical Standards}

Disclosures This study was funded by the National Oceanic and Atmospheric Administration, Chesapeake Bay Office (Award Number NA11NMF4570222).

Conflict of Interest The authors declare that they have no conflict of interest.

Open Access This article is distributed under the terms of the Creative Commons Attribution 4.0 International License (http:// creativecommons.org/licenses/by/4.0/), which permits unrestricted use, distribution, and reproduction in any medium, provided you give appropriate credit to the original author(s) and the source, provide a link to the Creative Commons license, and indicate if changes were made.

\section{References}

Adams, A.J., and R.K. Wolfe. 2007. Occurrence and persistence of nonnative Cichlasoma urophthalmus (family Cichlidae) in estuarine habitats of south-west Florida (USA): environmental controls and movement patterns. Marine and Freshwater Research 58: 921-930.

Alho, J.M. 1990. Logistic-regression in capture recapture models. Biometrics 46: 623-635.

Arnason, A.N., and K.H. Mills. 1981. Bias and loss of precision due to tag loss in jolly-Seber estimates for mark-recapture experiments. Canadian Journal of Fisheries and Aquatic Sciences 38: 10771095.

Arthington, A.H., N.K. Dulvy, W. Gladstone, and I.J. Winfield. 2016. Fish conservation in freshwater and marine realms: status, threats and management. Aquatic Conservation: Marine and Freshwater Ecosystems 26: 838-857.

Ashton, N.K., P.J. Anders, S.P. Young, and K.D. Cain. 2014. Coded wire tag and passive integrated transponder tag implantations in juvenile Burbot. North American Journal of Fisheries Management 34: 391400.

Barbour, A.B., M.S. Allen, T.K. Frazer, and K.D. Sherman. 2011. Evaluating the potential efficacy of invasive lionfish (Pterois volitans) removals. PLoS ONE 6(5):e19666.

Barker, R.J. 1997. Joint modeling of live-recapture, tag-resight, and tagrecovery data. Biometrics 53: 666-677.

Brennan, N.P., K.M. Leber, and B.R. Blackburn. 2007. Used of codedwire and visible implant elastomer tags for marine stock enhancement with juvenile red snapper Lutjanus campechanus. Fisheries Research 83: 90-97.

Burnham, K.P., D.R. Anderson, G.C. White, C. Brownie, and K.H. Pollock. 1987. Design and analysis methods for fish survival experiments based on release-recapture. American Fisheries Society Monograph 5: 1-437.

Cooch, E., and G. White, eds. 2016. MARK: a gentle introduction, 14th edition. Available at http://www.phidot.org/software/mark/docs/book/

Davis, J.P., E.T. Schultz, and J.C. Vokoun. 2012. Striped bass consumption of blueback herring during vernal riverine migrations: does relaxing harvest restrictions on a predator help conserve a prey species of concern? Marine and Coastal Fisheries 4: 239-251.

Edmonds, G. 2006. Spatial and temporal distributions of two nonindigenous predators in the Chesapeake Bay watershed. Richmond, Virginia: Master's thesis. Virginia Commonwealth University.

Evangelista, C., R.J. Britton, and J. Cucherousset. 2015. Impacts of invasive fish removal through angling on population characteristics and juvenile growth rates. Ecology and Evolution 5: 2193-2202.

Fabrizio, M.C., M.E. Holey, P.C. McKee, and M.L. Toneys. 1997. Survival rates of adult lake trout in northwestern Lake Michigan, 1983-1993. North American Journal of Fisheries Management 17: 413-428.

Garrett, D.L., and C.F. Rabeni. 2011. Intra-annual movement and migration of flathead catfish and blue catfish in the lower Missouri River and tributaries. In Conservation, ecology, and management of catfish: the second international symposium, ed. P. Michaletz and V. Travnichek. Bethesda, MD: American Fisheries Society.

Goulette, G.S., and C.A. Lipsky. 2016. Nonlethal batch identification of Atlantic Salmon using coded wire tags. North American Journal of Fisheries Management 36: 1084-1089.

Graham, K. 1999. A review of the biology and management of blue catfish. In Catfish 2000: proceedings of the international ictalurid symposium, ed. E.R. Irwin, W.A. Hubert, C.F. Rabeni, H.L. Schramm Jr., and T. Coon, vol. 24, 37-49. Bethesda MD: American Fisheries Society Symposium.

Greenlee, R.S., and C.N. Lim. 2011. Searching for equilibrium: population parameters and variable recruitment in introduced blue catfish populations in four Virginia tidal river systems. In Conservation, ecology, and management of catfish: the second international symposium, ed. P. Michaletz and V. Travnichek. Bethesda, MD: American Fisheries Society.

Hand, D.M., W.R. Brignon, D.E. Olson, and J. Rivera. 2010. Comparing two methods used to mark juvenile chinook salmon: automated and manual marking. North American Journal of Aquaculture 72: 10-17.

Huggins, R.M. 1989. On the statistical-analysis of capture experiments. Biometrika 76: 133-140.

Huggins, R.M. 1991. Some practical aspects of a conditional likelihood approach to capture experiments. Biometrics 47: 725-732.

Invasive Catfish Task Force. 2015. Final Report of the Sustainable Fisheries Goal Implementation Team. Annapolis, MD: NOAA Chesapeake Bay Office.

Jonsson, B., and N. Jonsson. 1993. Partial migration: niche shift versus sexual maturation in fishes. Reviews in Fish Biology and Fisheries 3: $348-365$.

Kendall, W. 2010. The 'robust design.' Chapter 15. In Cooch, E., and G. White, eds., MARK: a gentle introduction, 9th edition. Available at http://www.phidot.org/software/mark/docs/book/.

Kendall, W.L., and K.H. Pollock. 1992. The robust design in capturerecapture studies: a review and evaluation by Monte Carlo simulations. In Wildlife 2001: Populations, ed. D.R. McCullough and R.H. Barrett, 31-43. New York: Elsevier.

Kendall, W.L., R.J. Barker, G.C. White, M.S. Lindberg, C.A. Langtimm, and C.L. Penaloza. 2013. Combining dead recovery, auxiliary observations and robust design data to estimate demographic parameters from marked individuals. Methods in Ecology and Evolution 4: 828-835.

Kerr, L.A., D.H. Secor, and P.M. Piccoli. 2009. Partial migration of fishes as exemplified by the estuarine-dependent white perch. Fisheries 34: 114-123.

Lin, M., Y. Xia, B.R. Murphy, Z. Li, J. Liu, T. Zhang, and S. Ye. 2012. Size-dependent effects of coded wire tags on mortality and tag retention in redtail culter Culter mongolicus. North American Journal of Fisheries Management 32: 968-973.

Lorenz, O.T., S.A. Riccobono, and P. Smith. 2016. Effects of salinity on the survival and aggression of the invasive Rio Grande cichlid 
(Herichthys cyanoguttatus). Marine and Freshwater Behavior and Physiology 49: 1-8.

MacAvoy, S.E., G.C. Garman, and S.A. Macko. 2009. Anadromous fish as marine nutrient vectors. Fishery Bulletin 107: 165-174.

Magoro, M.L., A.K. Whitfield, and L. Carassou. 2015. Predation by introduced largemouth bass Micropterus salmoides on indigenous marine fish in the lower Kowie River, South Africa. African Journal of Aquatic Science 40: 81-88.

Norris, A.J., D.R. DeVries, and R.A. Wright. 2010. Coastal estuaries as habitat for a freshwater fish species: exploring population-level effects of salinity on largemouth bass. Transactions of the American Fisheries Society 139: 610-625.

Pollock, K.H. 1981. Capture-recapture models allowing for agedependent survival and capture rates. Biometrics 37: 521-529.

Pollock, K. 1982. A capture-recapture design robust to unequal probability of capture. Journal of Wildlife Management 46: 757-760.

Pollock, K. H., J. D. Nichols, C. Brownie, and J. E. Hines. 1990. Statistical inference for capture-recapture experiments. Wildlife Monographs Number 107: 1-97.

Pollock, K.H., J. Yoshizaki, M.C. Fabrizio, and S.T. Schram. 2007. Factors affecting survival rates of a recovering lake trout population estimated by mark-recapture in Lake Superior, 1969-1996. Transactions of the American Fisheries Society 136: 185-194.

Rehage, J.S., D.P. Lopez, M.Y. Anderson, and J.E. Serafy. 2015. On the mismatch between salinity tolerance and preference for an invasive fish: a case for incorporating behavioral data into niche modeling. Journal of Experimental Marine Biology and Ecology 471: 58-63.

Schloesser, R.W., M.C. Fabrizio, R.J. Latour, G.C. Garman, R. Greenlee, M. Groves, and J. Gartland. 2011. Ecological role of blue catfish (Ictalurus furcatus) in Chesapeake Bay communities and implications for management. In Conservation, ecology, and management of catfish: the second international symposium, ed. P. Michaletz and V. Travnichek. Bethesda, MD: American Fisheries Society.

Schmitt, J.D., E.M. Hallerman, A. Bunch, Z. Moran, J.A. Emmel, and D.J. Orth. 2017. Predation and prey selectivity by nonnative catfish on migrating alosines in an Atlantic slope estuary. Marine and Coastal Fisheries 9: 108-125.

Scott, D.M., J. Rabineau, R.W. Wilson, D.J. Hodgson, and J.A. Brown. 2008. Can pikeperch colonise new freshwater systems via estuaries? Evidence from behavioral salinity tests. Marine and Freshwater Research 59: 694-702.

Simon, J., and H. Doerner. 2011. Growth, mortality and tag retention of small Anguilla anguilla marked with visible implant elastomer tags and coded wire tags under laboratory conditions. Journal of Applied Ichthyology 27: 94-99.

Tsehaye, I., M. Catalano, G. Sass, D. Glover, and B. Roth. 2013. Propects for fishery-induced collapse of invasive Asian carp in the Illinois River. Fisheries 38: 445-454.

Tuckey, T.D., and M.C. Fabrizio. 2016a. Variability in fish tissue proximate composition is consistent with indirect effects of hypoxia in Chesapeake Bay tributaries. Marine and Coastal Fisheries 8: 1-15.

Tuckey, T. D., and M. C. Fabrizio. 2016b. Estimating relative juvenile abundance of ecologically important finfish in the Virginia portion of Chesapeake Bay. Final Report to the Virginia Marine Resources Commission, prepared by the Virginia Institute of Marine Science. July 2016, Available at: doi. 10.21220/V5W30G

Tuckey, T.D., M.C. Fabrizio, A.J. Norris, and M. Groves. Low apparent survival and heterogeneous movement patterns of invasive blue catfish (Ictalurus furcatus) in a coastal river. Marine and Coastal Fisheries. in review.

Vander Haegen, G.E., A.M. Swanson, and H.L. Blankenship. 2002. Detecting coded wire tags with handheld wands: effectiveness of two wanding techniques. North American Journal of Fisheries Management 22: 1260-1265.

White, G.C., and K.P. Burnham. 1999. Program MARK: survival estimation from populations of marked animals. Bird Study 46: 120-139.

White, G.C., and E.G. Cooch. 2017. Population abundance estimation with heterogeneous encounter probabilities using numerical integration. The Journal of Wildlife Management 81: 322-336. 